\title{
Synthesis and adsorption properties of ZIF-8 nanoparticles using a micromixer
}

\section{$\operatorname{AUTHOR}(\mathrm{S}):$}

Yamamoto, Daigo; Maki, Taisuke; Watanabe, Satoshi; Tanaka, Hideki; Miyahara, Minoru T.; Mae, Kazuhiro

\section{CITATION:}

Yamamoto, Daigo ... [et al]. Synthesis and adsorption properties of ZIF-8 nanoparticles using a micromixer. Chemical Engineering Journal 2013, 227: 145-150

\section{ISSUE DATE:}

2013-07-01

URL:

http://hdl.handle.net/2433/176334

\section{RIGHT:}

C 2012 Elsevier B.V.; この論文は出版社版でありません。引用の際には 出版社版をご確認ご利用ください。; This is not the published version. Please cite only the published version. 


\title{
Synthesis and Adsorption Properties of ZIF-8 Nanoparticles Using a Micromixer
}

Daigo Yamamoto, Taisuke Maki, Satoshi Watanabe, Hideki Tanaka, Minoru T. Miyahara, and

\author{
Kazuhiro Mae*
}

Department of Chemical Engineering, Kyoto University, Katsura, Nishikyo, Kyoto 615-8510, Japan

kaz@cheme.kyoto-u.ac.jp

Tel:+81-75-383-2668

Fax:+81-75-383-2658

* Corresponding author 


\section{Abstract}

We synthesized size-controlled zeolitic imidazolate framework (ZIF-8) nanoparticles using a T-type micromixer. The nanocrystallization of ZIF-8 proceeds by a rapid coordination reaction of $\mathrm{Zn}^{2+}$ ions and 2-methylimidazole (2-MeIM) in a highly concentrated solution. Therefore, a rapid mixing of the raw materials is required to control the size and morphology of ZIF-8 nanoparticles. First, we prepared ZIF-8 nanoparticles at various flow rates of raw materials to investigate the mixing performance of a T-type micromixer. The size of the ZIF-8 nanoparticles decreased with an increase in flow rates at Reynolds number $(R e)<2000$ (regarded as laminar flow). However, the size and shape of the resultant nanoparticles did not depend on the flow rates at $R e>2000$ (transition state between laminar flow and turbulent flow), demonstrating the high mixing performance. Further, we systematically examined the effects of temperatures and $[2-\mathrm{MeIM}] /\left[\mathrm{Zn}^{2+}\right]$ ratios on the resultant ZIF-8 nanoparticles to elucidate the formation mechanism and to optimize the conditions for the synthesis of smaller ZIF-8 nanoparticles. Through a detailed analysis, we concluded that the requisite conditions are lower temperatures and higher $[2-\mathrm{MeIM}] /\left[\mathrm{Zn}^{2+}\right]$ ratios, which affect the nucleation process and the particle growth process, respectively. Finally, we examined the adsorption properties of the resultant smaller ZIF-8 nanoparticles. We found that the amount of adsorbed $\mathrm{N}_{2}$ gas for the ZIF-8 nanoparticles synthesized by our method is higher than the amount for a conventional ZIF-8 sample, and the adsorption rate is faster because of the 
nanocrystallization.

\section{Introduction}

Porous coordination polymers (PCPs), also known as metal organic frameworks (MOFs), are unique materials with regular pore structures [1]. They can be used for gas storage, for catalysis and as drug delivery systems [2]. PCP/MOFs are synthesized by an assembly process involving continuous coordinate bond formation between metal ions $\left(\mathrm{Zn}^{2+}, \mathrm{Cu}^{2+}, \mathrm{Ni}^{2+}, \mathrm{Co}^{3+}\right.$, etc. $)$ and organic ligands (e.g., dicarboxylic acid or amines). In particular, the series of zeolitic imidazolate frameworks (ZIFs) is a highly useful class of porous materials because ZIFs are chemically and thermally stable [3].

PCP/MOFs have three advantages over other porous materials. First, they possess microscopic pores $(<2 \mathrm{~nm})$ and large surface areas; their Brunauer-Emett-Teller (BET) specific surface area $\left(1,000 \sim 5,000 \mathrm{~m}^{2} \cdot \mathrm{g}^{-1}\right)$ is larger than the BET specific surface area of activated carbon $\left(1,000 \mathrm{~m}^{2} \cdot \mathrm{g}^{-1}\right)$ and of zeolites $\left(\sim 1,000 \mathrm{~m}^{2} \cdot \mathrm{g}^{-1}\right)$. Second, innumerable PCP/MOFs with various kinds of shape and structure can be synthesized by selecting different combinations of metal ions and organic ligands. Therefore, the pore size of PCP/MOFs can be controlled in the order of angstroms by altering the chain length of the organic ligands, which enables the design of adsorption materials suited for target guest molecules. Bux et al. demonstrated that ZIF-8, one of a ZIF series, can separate hydrogen (molecular diameter $=2.9 \AA)$ from larger molecules, such as methane $(3.8 \AA)$, 
because of its narrow pores with a regular size (3.4 $\AA$ ) [4]. Third, some PCP/MOFs have structural flexibility, leading to a unique adsorption behavior, the gate adsorption phenomenon, that is not classified into any isotherm types of the International Union of Pure and Applied Chemistry (IUPAC) [5]. Due to the above advantages, PCP/MOFs can be expected to serve as a new class of functional adsorption materials.

The conventional synthesis of PCP/MOFs was carried out by a slow coordination reaction over the course of days using a solvothermal method [6]. Thus, crystal growth proceeds to be over micrometers in size. In contrast, several other research groups have synthesized a variety of nanocrystallized PCP/MOFs in recent years [7-14]. The nanoparticles can be expected to have different interface properties, such as sorption kinetics and catalytic activity, from the bulk because of the increase in the specific surface area and the decrease in the diffusion length. Furthermore, the properties would depend on the morphology of the materials as well as on crystal size. Diring et al. demonstrated that sorption isotherms varied with the morphology of $\left[\mathrm{Cu}_{3}(\mathrm{btc})_{2}\right]$ frameworks (where btc represents benzene-1,3,5-tricarboxylate) [12]. Thus, strict control of the size and shape of the materials is required to design their functions.

ZIF-8 nanoparticles are synthesized by a rapid coordination reaction at room temperature with high concentrations of $\mathrm{Zn}^{2+}$ ions and 2-methylimidazole (2-MeIM) instead of by a conventional slow reaction by solvothermal synthesis $[10,14]$. However, in previous studies, the 
nanocrystallization of PCP/MOFs including ZIF-8 was carried out using a batch reactor system, despite the fast reaction. No other study has been reported on the synthesis of PCP/MOF nanoparticles by controlling the mixing performance of metal ions and organic ligands, although the mixing process would affect the size and shape of the resultant nanoparticles.

A micromixer is a possible tool to accomplish rapid mixing, which offers a homogenous reaction field. Therefore, it is an effective device for the diffusion-controlled reaction. It has a substantially higher mixing performance than a batch reactor because molecular diffusion becomes dominant in microspaces. In particular, the yields and selectivity of rapid reactions such as the Villermaux/Dushman reaction and the Friedel-Craft reactions, which occur on the order of seconds, improve remarkably [15-17]. In addition, rapid heat control is achieved on the order of milliseconds due to the increase in heat transfer area, suggesting that the micromixer should also be useful for reactions with large enthalpy changes [18]. In theory, the time scale $(t)$ of molecular diffusion and conduction heat transfer is proportional to the square of the characteristic distance $(L)$, that is, $t \propto L^{2}$. The inner diameter of a micromixer corresponds to the characteristic distance. That is to say, a scale-down of the inner diameter by $1 / 10$ produces a 100 -fold higher efficiency of mixing and heat transfer.

A micromixer with the above functions can be used to synthesize monodispersed and size-controlled nanoparticles $[19,20]$. The mechanism of particle synthesis is explained based on a 
LaMer diagram (Fig. 1), where $C^{*}{ }_{\min }$ and $C_{\mathrm{s}}$ represent critical supersaturation and the solubility of a reaction product, respectively. This diagram illustrates the time course of the product concentration (C) during particle synthesis. The process involves three steps: 1 . an increase of the product concentration $\left(t<t_{1}\right)$, 2. rapid nucleation $\left(t_{1}<t<t_{2}\right)$, and 3. particle growth $\left(t_{2}<t<t_{3}\right)$. A micromixer can control the nucleation process and the particle growth process because of its high efficiency in mixing and heat transfer.

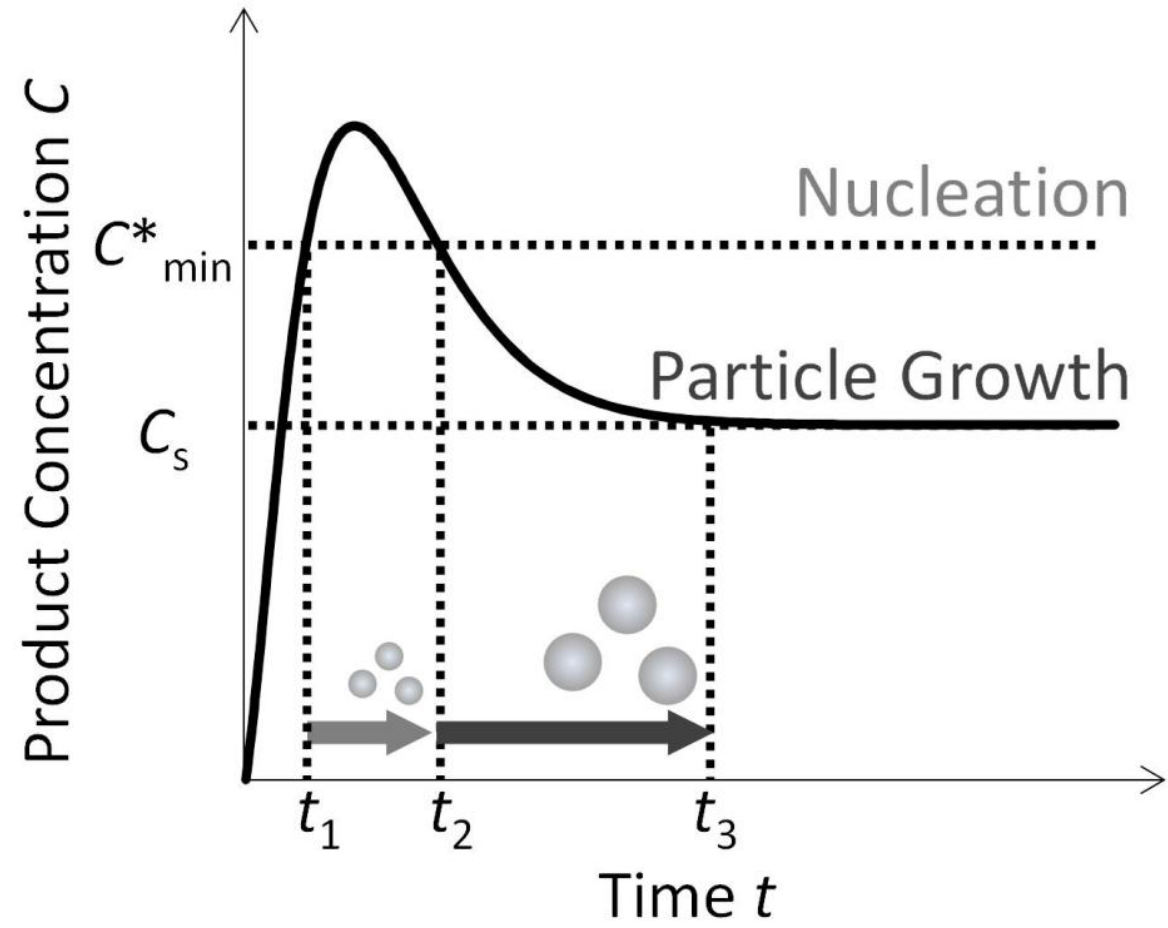

In this study, we prepared ZIF-8 nanoparticles using a T-type micromixer and examined the effect of its mixing performance, temperatures, and concentrations of raw materials on the size and morphology of resultant ZIF-8 particles. Furthermore, the adsorption properties, such as the adsorption isotherms and adsorption rates of the resultant particles, were investigated and compared 
with a commercial ZIF-8 sample.

\section{Experimental}

\section{1. Chemicals.}

2-methylimidazole (2-MeIM, 99\%) and zinc nitrate hexahydrate (98\%) were obtained from Aldrich Chemical Co. ZIF-8 powder (2-methylimidazole zinc) was also purchased from Aldrich Chemical Co. and used to evaluate the characteristics of the ZIF-8 particles prepared in this study. Ultrapure deionized (DI) water (18 $\mathrm{M} \Omega \cdot \mathrm{cm}$, Millipore) was used for sample preparation. All chemicals were used without further purification.

\section{2. Preparation of ZIF-8 nanoparticle suspensions.}

Fig. 2 shows the experimental setup for the synthesis of ZIF-8 nanoparticles using a T-type micromixer purchased from Swagelok Co. with an inner diameter of $330 \mu \mathrm{m}$. The preparation of ZIF-8 nanoparticles was carried out in an excess of 2-MeIM to achieve the rapid coordination reaction, although the stoichiometric proportion of the reaction $\left([2-\mathrm{MeIM}]:\left[\mathrm{Zn}^{2+}\right]\right)$ is $2: 1$. An aqueous 2-MeIM solution of various concentrations (typically $3.5 \mathrm{M}$ in the standard preparation) and an aqueous zinc nitrate solution (set to be $0.05 \mathrm{M}$ ) were mixed using the T-type micromixer at various temperatures. The flow rates $(v)$ of the 2-MeIM solution and the zinc nitrate one were equal and were adjusted in a range from $1 \mathrm{ml} \cdot \mathrm{min}^{-1}$ to $40 \mathrm{ml} \cdot \mathrm{min}^{-1}$ with a syringe pump (PHD2000, 
HARVARD). The mixed solution from the outlet of the micromixer turned white immediately. The solution was aged for $1 \mathrm{~h}$ to obtain a ZIF-8 nanoparticle suspension.

\section{2-methylimidazole}

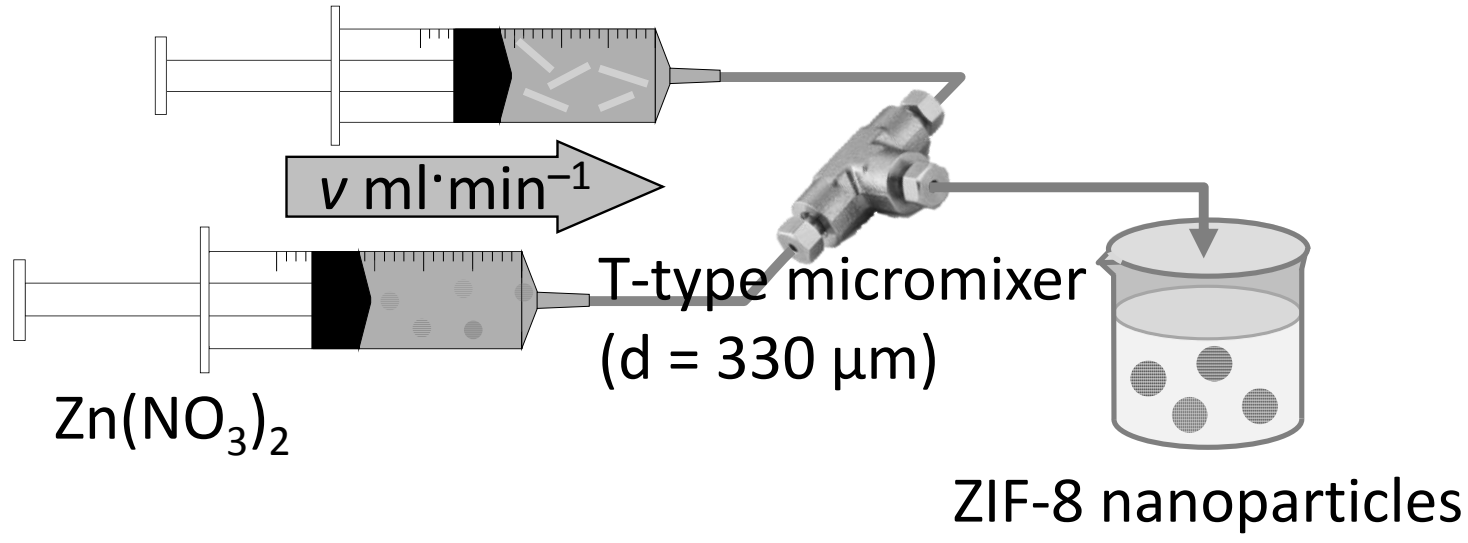

Fig. 2

ZIF-8 particles were also prepared using a batch reactor system as a control and synthesized by a similar procedure to the one proposed by Pan et al. [14], which is briefly explained below. An aqueous 2-MeIM solution $(15 \mathrm{ml}, 3.5 \mathrm{M})$ was added to an aqueous zinc nitrate solution $(15 \mathrm{ml}, 0.05 \mathrm{M})$ with vigorous stirring for $1 \mathrm{~h}$. This solution also turned white.

\section{3. Characterizations}

The UV-vis absorbance spectra of the mixed solution from the outlet were measured at regular intervals (0.1 s intervals) over a period of $10 \mathrm{~min}$ on a Shimadzu MultiSpec-1500 spectrophotometer with quartz cells (path length: $2 \mathrm{~mm}$ ). The median size of the resultant ZIF- 8 nanoparticles dispersed in the solution was measured by dynamic light scattering (DLS) using a nanoparticle analyzer (SZ-100, Horiba Co.). The dynamic viscosity of the solution was also 
measured using a viscometer (Viscometer SV-10, A\&D Co.).

The ZIF-8 particles dispersed in the solution were collected by centrifuging at 10,000 rpm for 30 min with a high-speed centrifuge (H-1500F, KOKUSAN) and then washed several times with DI water. The product was dried under vacuum for $12 \mathrm{~h}$ at $100{ }^{\circ} \mathrm{C}$ in a drying oven to obtain the powder. A sample of the powder was identified by powder x-ray diffraction (XRD) patterns at room temperature on a X-ray diffractometer (Multiflex, RIGAKU Corp.) in transmission geometry using $\mathrm{Cu} \mathrm{K} \alpha 1$ radiation $(\lambda=1.540562 \AA)$ at $20 \mathrm{kV}$ and $20 \mathrm{~mA}$.

The powder was also observed under a scanning electron microscope (SEM) (JSM-6700F field emission SEM, JEOL). The samples for SEM observation were prepared by placing a drop of a ZIF-8 nanoparticle suspension re-dispersed in DI water on a mica substrate, which was then dried in vacuum.

The sorption isotherms and kinetics of the obtained ZIF-8 powder and the commercial powder (ca. $0.03 \mathrm{~g}$ ) for $\mathrm{N}_{2}$ gas at $77 \mathrm{~K}$ were recorded on a BELSORP-max volumetric-adsorption instrument from BEL Japan, Inc. The sorption kinetics was analyzed by measuring the vapor pressure of $\mathrm{N}_{2}$ gas from about $P / P_{0}=0.25$ to an equilibrium pressure during adsorption.

\section{Results and discussion}

\section{1. Preparation}


Fig. 3 shows the powder XRD patterns of an as-synthesized ZIF-8 sample prepared using a T-type micromixer and a commercial sample. The agreement between the patterns demonstrates that the product is a pure ZIF-8 material. To examine the dynamics of ZIF-8 particle formation, we measured the UV-vis absorbance spectra of the mixed solution from the outlet of the T-type micromixer for various aging periods (Fig. 4a). The absorbance in the visible region increased with time, resulting from the immediate transformation from a colorless solution to a white ZIF-8 particle suspension. We investigated the time course of absorbance at $500 \mathrm{~nm}$ in the mixed solution to further examine the formation kinetics of ZIF-8 particles (Fig. 4b). The absorbance increased rapidly for $100 \mathrm{~s}$ after an induction period of $20 \mathrm{~s}$. This pattern indicates that a nucleation process occurs at an early stage $(<20 \mathrm{~s})$ and that particle growth was dominant after $20 \mathrm{~s}$ and almost completed in $100 \mathrm{~s}$. The products obtained by such a rapid reaction are thought to depend on the mixing performance of the raw materials. 


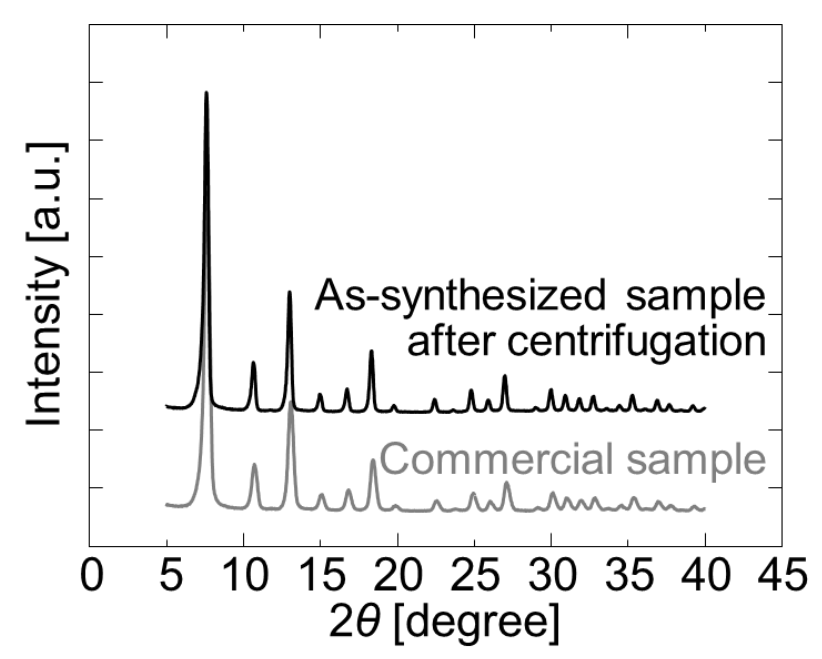

Fig. 3

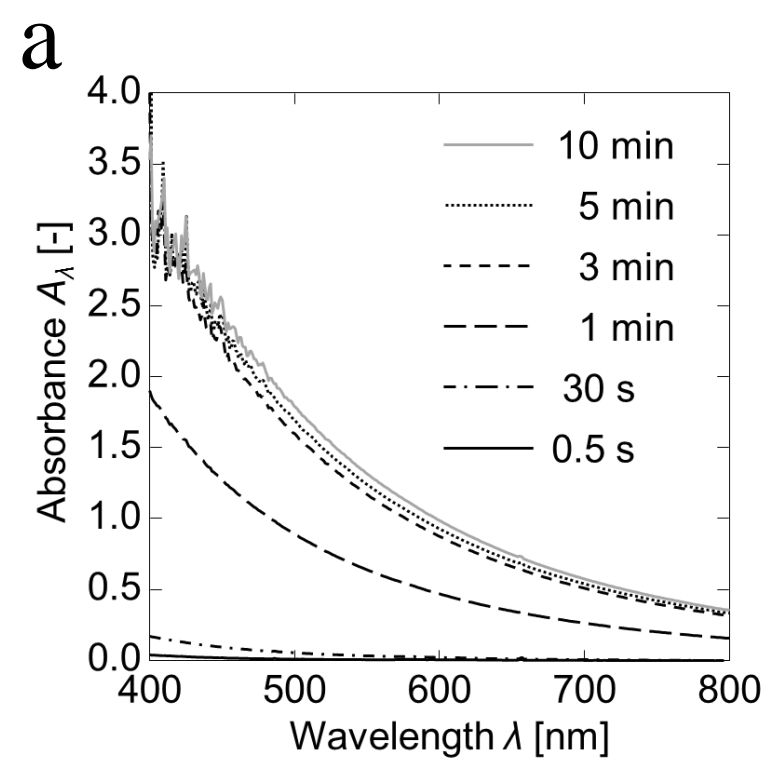

$\mathrm{b}$

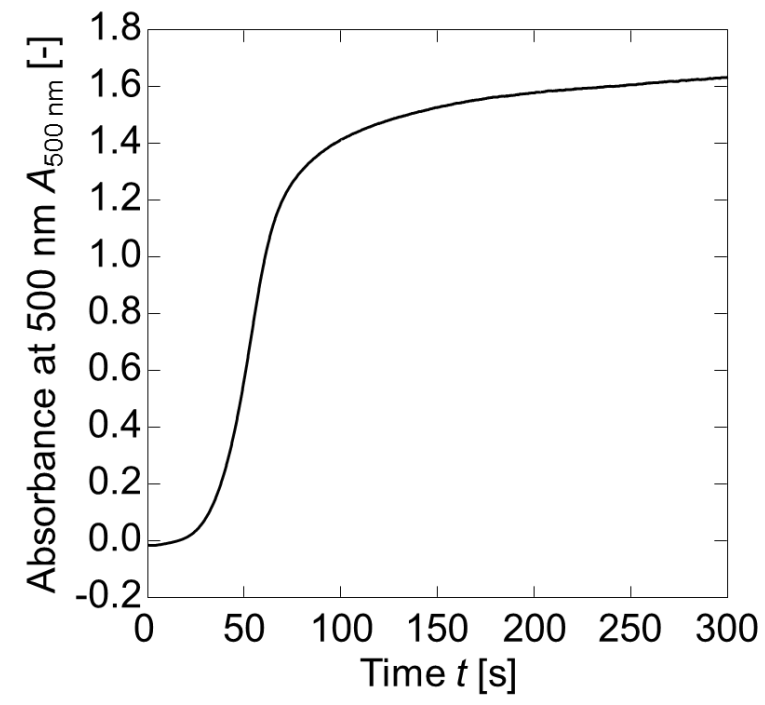

Fig. 4

The synthesis of ZIF-8 particles using a batch reactor system produced quite different results in different trials, despite identical conditions. We prepared ZIF-8 nanoparticles using a batch reactor system over 20 times under the same concentration conditions. Fig. 5 shows the 
median size of the resultant ZIF-8 particles after each trial. The median size of the nanoparticles was different among the trials $\left(\mathrm{D}_{\mathrm{p} 50}=343.9 \pm 341.2 \mathrm{~nm}\right)$, indicating that a batch reactor offers low reproducibility in the rapid synthesis of ZIF-8 nanoparticles because of heterogeneous mixing.

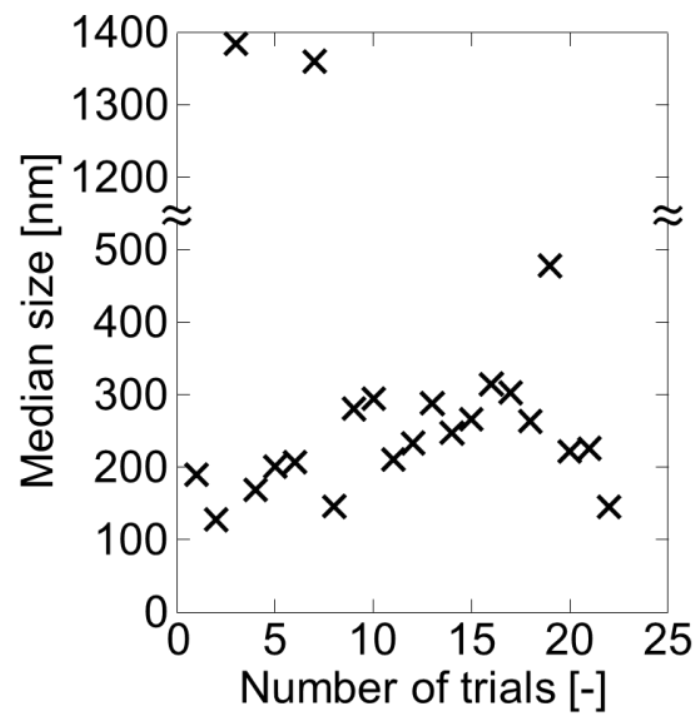

Fig. 5

We examined the effect of the flow rates of raw materials on the size of the resultant ZIF-8 nanoparticles to investigate the mixing performance of a T-type micromixer (Fig. 6). The Reynolds number $(R e)$ is defined by the following equation:

$R e=\frac{\rho U L}{\mu}$

where $\rho, U, L$, and $\mu$ represent the density of the fluid, the fluid velocity, the characteristic distance (pipe diameter $=330 \mu \mathrm{m}$ ), and the dynamic viscosity of the fluid, respectively. The density of the resultant ZIF-8 nanoparticle suspension was measured to be $1.01 \mathrm{~g}^{\cdot} \mathrm{cm}^{-3}$. The dynamic viscosity was measured to be $1.35 \times 10^{-3} \mathrm{~Pa}^{\cdot} \mathrm{s}$ at room temperature, which is higher than the dynamic viscosity of 
pure water $\left(0.89 \times 10^{-3} \mathrm{~Pa} \cdot \mathrm{s}\right.$ at $\left.25^{\circ} \mathrm{C}\right)$ because of the high concentration of 2-MeIM. $U$ was calculated as follows:

$U=\frac{4 v_{\text {total }}}{\pi L^{2}}$

where $v_{\text {total }}$ is the total flow rates of the raw materials $\left(v_{\text {total }}=2 v\right)$. Thus, $R e$ can be calculated at arbitrary flow rates. As shown in Fig. 6, the size decreased with increasing flow rates at $R e<2000$ (regarded as laminar flow), suggesting that the mixing performance improves at higher $R e$ because of an increase in the shearing force between the fluids of raw materials. On the other hand, higher flow rates did not change the nanoparticle size at $R e>2000$ (transition state between laminar flow and turbulent flow), demonstrating sufficiently high mixing performance to mix the raw materials. Fig. 7a and $\mathrm{b}$ show SEM images in the cases of flow rates of $1 \mathrm{ml} \cdot \mathrm{min}^{-1}$ and $30 \mathrm{ml} \cdot \mathrm{min}^{-1}$, respectively. The slower flow rate of $1 \mathrm{ml} \cdot \mathrm{min}^{-1}$ led to larger particles with a polygonal shape, while the higher rate of $30 \mathrm{ml} \cdot \mathrm{min}^{-1}$ yielded smaller, roughly spherical particles. This result suggests that the size and shape of ZIF-8 nanoparticles can be controlled by changing the flow rates. We also confirmed that ZIF-8 nanoparticle suspensions prepared at flow rates of over $20 \mathrm{ml} \cdot \mathrm{min}^{-1}$ were dispersed in solution for a week, while precipitates were observed after a few days for the suspension obtained at $1 \mathrm{ml} \cdot \mathrm{min}^{-1}$ and the commercial sample dispersed in DI water. Therefore, subsequent experiments were carried out at the flow rate of $25 \mathrm{ml} \cdot \mathrm{min}^{-1}$, which provides a sufficiently high mixing performance. 


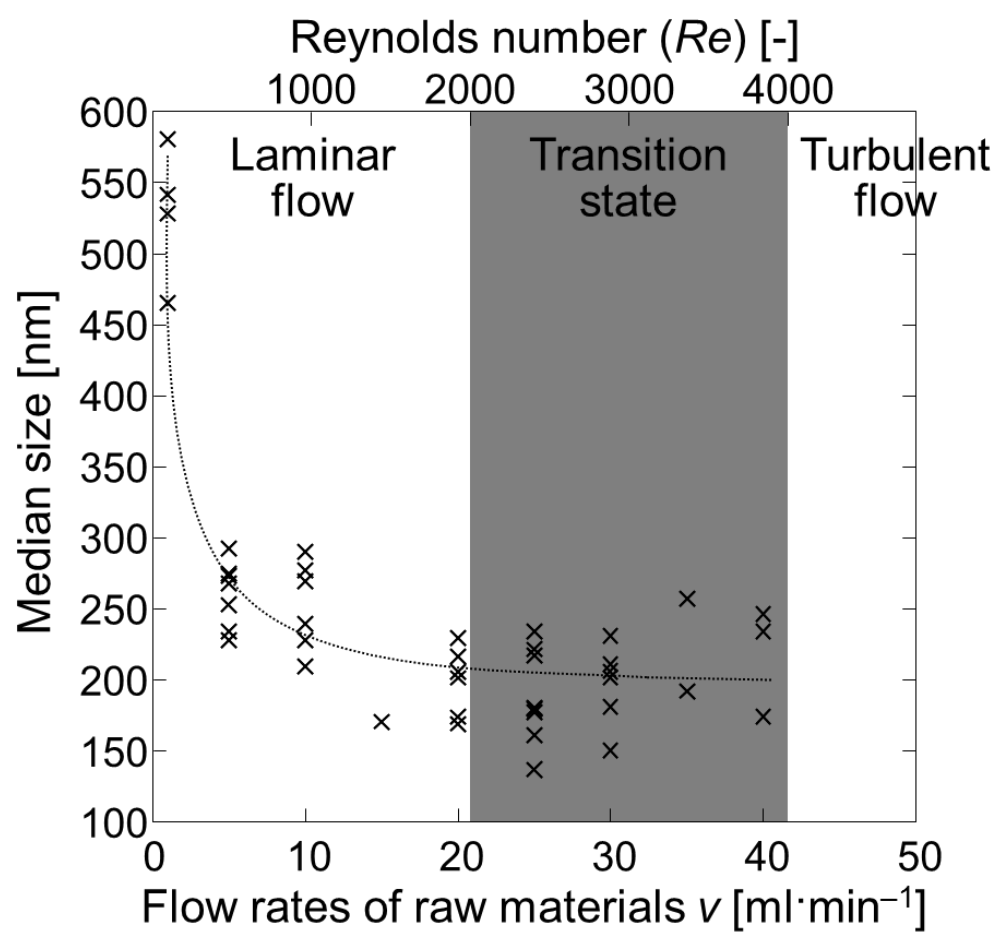

Fig. 6
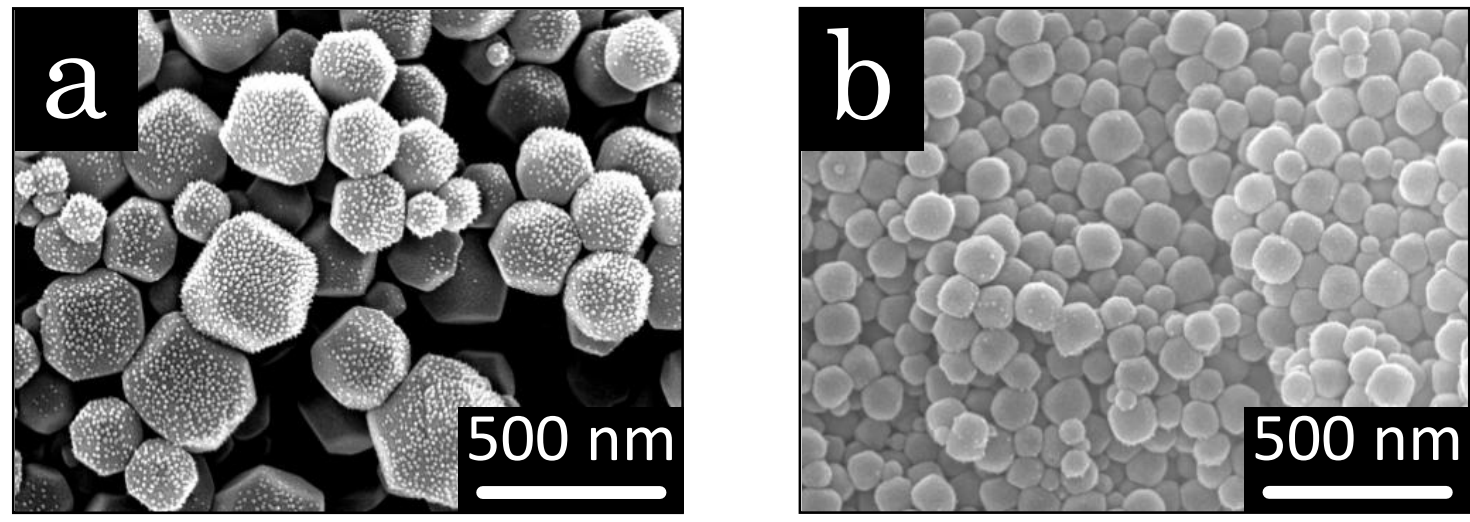

Fig. 7

\subsection{Size control}

We attempted to regulate of the nucleation process and the particle growth process (see Fig.

1) to control the size of the particles. Temperature is an available factor to control the nucleation process because the solubility of the materials $\left(C_{\mathrm{s}}\right)$ depends on temperature. In general, solubility 
drops at lower temperatures, which makes nucleation more probable because of the high degree of supersaturation $\left(C / C_{\mathrm{s}}\right)$. Fig. 8 shows the effect of temperatures on the size of ZIF-8 nanoparticles. Lower temperatures produced ZIF-8 nanoparticles with a smaller size because the high degree of supersaturation resulting from lower solubility increases the number of nuclei during the nucleation process.

Further, we investigated the effect of $[2-\mathrm{MeIM}] /\left[\mathrm{Zn}^{2+}\right]$ ratios on the size of $\mathrm{ZIF}-8$ nanoparticles to control the subsequent particle growth process (Fig. 9). The addition of 2-MeIM in greater excess yielded smaller ZIF-8 nanoparticles, while precipitates were formed for a few hours at lower values of the ratio $\left([2-\mathrm{MeIM}] /\left[\mathrm{Zn}^{2+}\right]<4\right)$. This result demonstrates that the particle surface is covered with an excess of 2-MeIM at higher [2-MeIM]/[ $\left.\mathrm{Zn}^{2+}\right]$ ratios, which depresses the particle growth of ZIF-8. On the other hand, particle growth and aggregation proceed at lower ratios because the 2-MeIM and $\mathrm{Zn}^{2+}$ ions can continue to link with each other. 


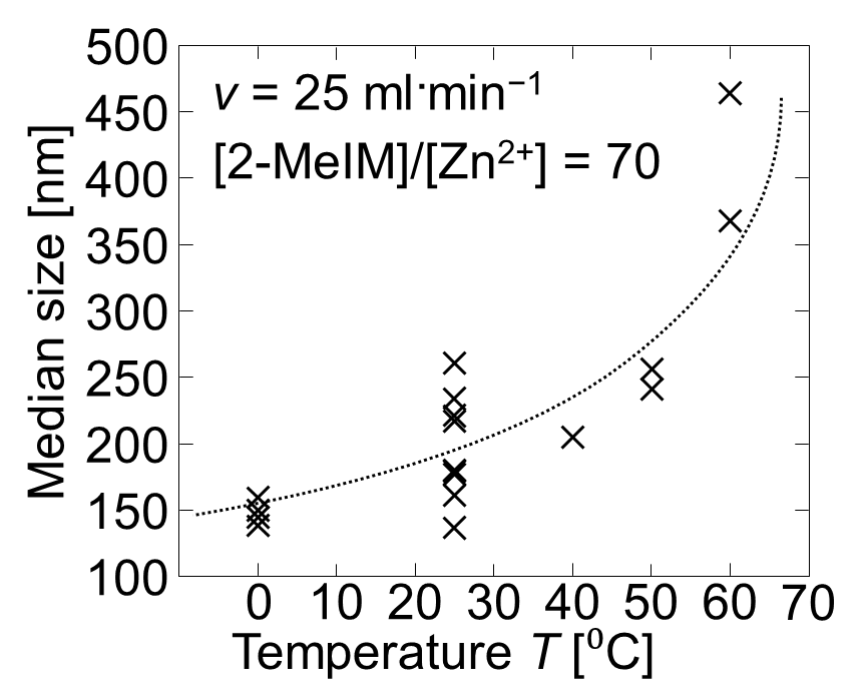

Fig. 8

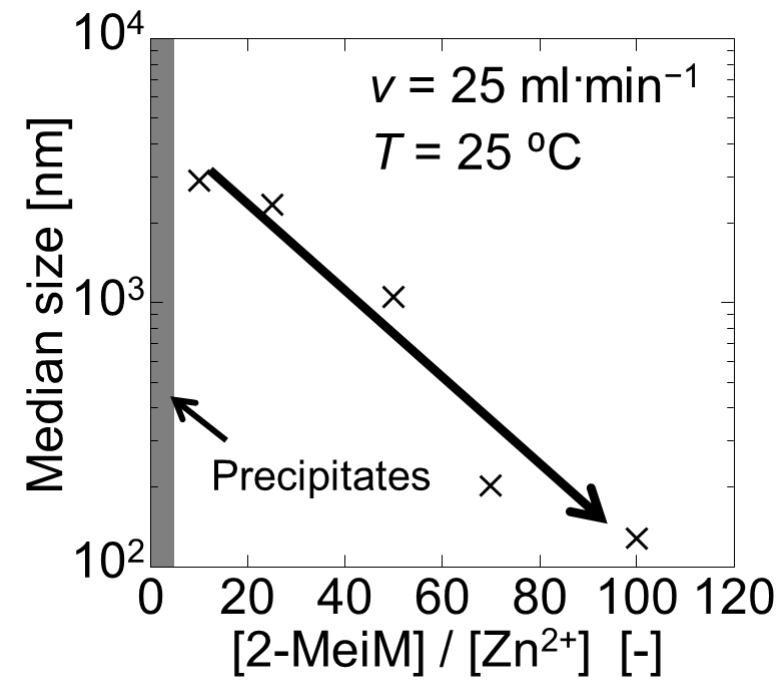

Fig. 9

Based on these results, we propose a mechanism for ZIF-8 nanoparticle formation by the rapid coordination reaction (Fig. 10). The nucleation process can be controlled by changing temperatures, that is, lower temperatures produce more nuclei, resulting in smaller nanoparticles. The $[2-\mathrm{MeIM}] /\left[\mathrm{Zn}^{2+}\right]$ ratios affect the particle growth process, and higher ratios inhibit particle growth and aggregation because the particle surface is covered with 2-MeIM. We can control the size and shape of ZIF-8 nanoparticles by changing the mixing performance, temperature, and $[2-\mathrm{MeIM}] /\left[\mathrm{Zn}^{2+}\right]$ ratio. A suitable procedure for the preparation of smaller ZIF-8 nanoparticles is rapid mixing with a higher $[2-\mathrm{MeIM}] /\left[\mathrm{Zn}^{2+}\right]$ ratio at a lower temperature. We expect that a micromixer can be applied to the rapid synthesis of other PCP/MOF nanoparticles, including the ZIF series, because it can strictly control both temperature and mixing performance. 


\section{Synthesis of ZIF-8 nanoparticles}
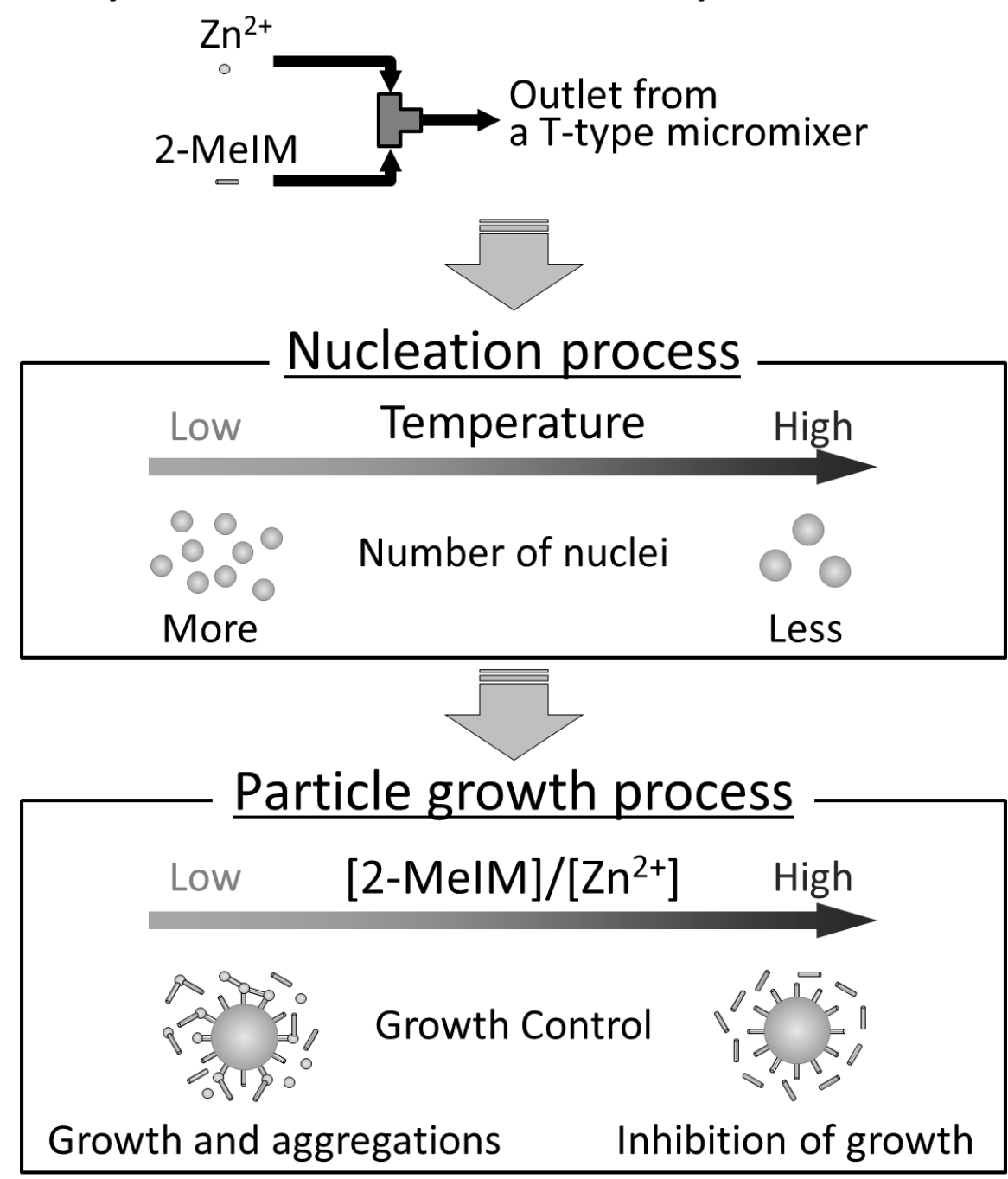

Fig. 10

\section{3. Characterization of $\mathbf{N}_{2}$ Gas Sorption Properties.}

Fig. 11a shows the $\mathrm{N}_{2}$ adsorption isotherms of the smaller ZIF-8 sample, which was obtained at the $[2-\mathrm{MeIM}] /\left[\mathrm{Zn}^{2+}\right]$ ratio of 70 at $0{ }^{\circ} \mathrm{C}$, and of the commercial sample at $77 \mathrm{~K}$. We found that $\mathrm{N}_{2}$ uptake by the ZIF-8 nanoparticles is slightly higher than the uptake by the commercial sample because of the increase in the specific surface area of ZIF-8.

Furthermore, we analyzed the $\mathrm{N}_{2}$ adsorption rate to investigate the adsorption kinetics (Fig. 
11b). The relative concentration difference $(f)$ of vapor $\mathrm{N}_{2}$ gas between arbitrary times and the equilibrium state was calculated using the following equation:

$f=\frac{\mathrm{c}_{\mathrm{t}}-c_{\mathrm{eq}}}{c_{\mathrm{e}}-c_{\mathrm{eq}}}$

where, the subscripts $0, t$, eq denote the immediate time after introduction of $\mathrm{N}_{2}$ gas, an arbitrary time, and the equilibrium condition, respectively. A shorter time was taken to accomplish adsorption equilibrium in the case of smaller ZIF-8 nanoparticles, and the time taken for $f$ to drop below 5\% was $2 / 3$ as long (56 s) as the time for the commercial sample (91 s) because of the decrease in diffusion length in pores caused by nanocrystallization. We found that the ZIF-8 nanoparticles obtained in our study would be adsorption materials superior to the conventional ZIF-8 materials.
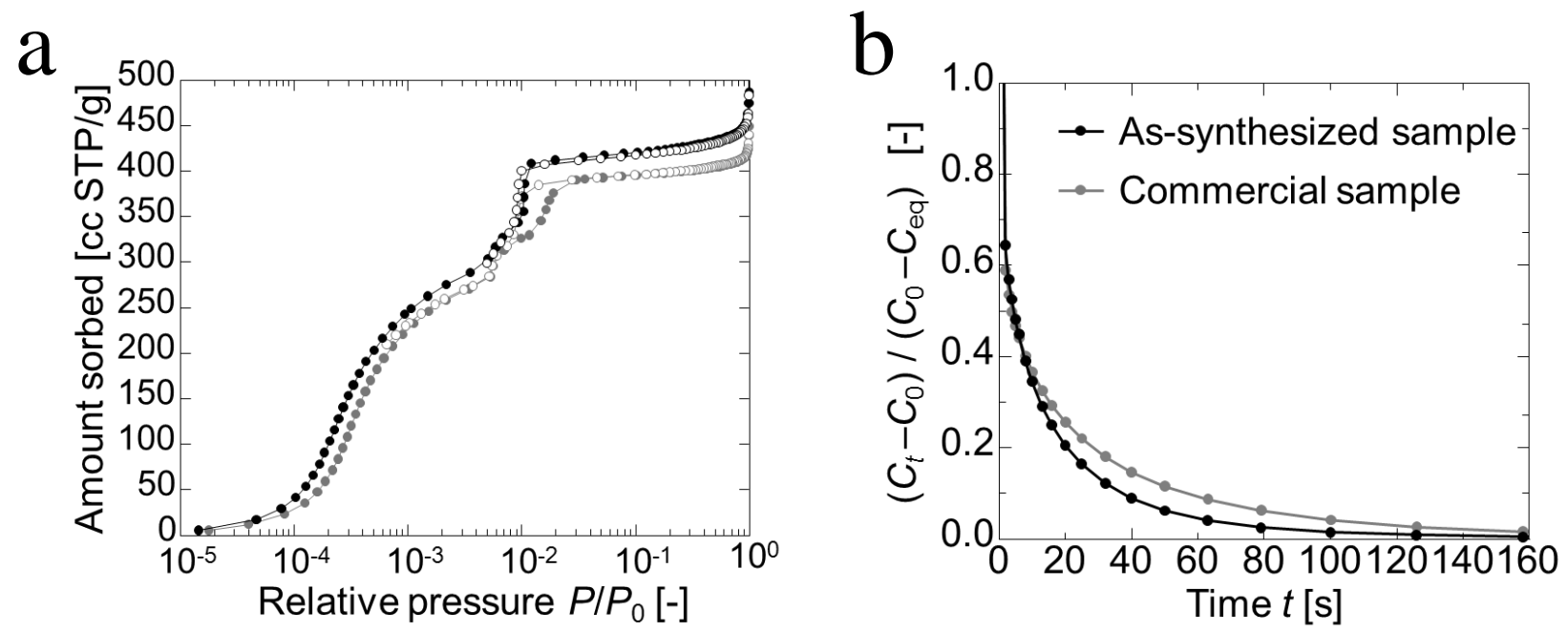

Fig. 11

\section{Conclusions.}

We attempted the synthesis of ZIF-8 nanoparticles using a T-type micromixer and 
investigated the effects of the flow rates, temperatures, and ratios of concentrations of raw materials ([2-MeIM]/[ $\left.\left.\mathrm{Zn}^{2+}\right]\right)$. We arrived at the following conclusions:

(1) Particle size becomes smaller with an increase in flow rates at $R e<2000$ (laminar flow), demonstrating an increase in mixing performance. However, a sufficiently high mixing performance is accomplished at $R e>2000$ (transition state between laminar flow and turbulent flow). Thus, at that point, the size and shape of the resultant nanoparticles no longer depend on flow rates.

(2) We can control the nucleation process and the particle growth process by changing the temperatures and $[2-\mathrm{MeIM}] /\left[\mathrm{Zn}^{2+}\right]$ ratios. In brief, lowering temperatures increases the number of nuclei during the nucleation process, leading to smaller nanoparticles. However, the $[2-\mathrm{MeIM}] /\left[\mathrm{Zn}^{2+}\right]$ ratios affect the subsequent particle growth process. An excess of [2-MeIM] slows particles from growing by covering the ZIF-8 particle surface with 2-MeIM.

(3) The amount of adsorbed $\mathrm{N}_{2}$ gas for the resultant ZIF-8 nanoparticles is higher than for the conventional ZIF-8 sample. Furthermore, the adsorption rate is faster because of the decrease in diffusion length in the pores.

\section{ACKNOWLEDGMENT}


This study was partly supported by the Program for Fostering Regional Innovation, Kyoto Environmental Nanotechnology Cluster.

\section{FIG. CAPTIONS}

Fig. 1. Scheme of particle synthesis based on LaMer diagram. The synthetic mechanism involves a nucleation process and a particle growth process.

Fig. 2. Experimental setup for the synthesis of a ZIF-8 nanoparticle suspension using a T-type micromixer.

Fig. 3. Powder XRD patterns of an as-synthesized ZIF-8 sample and a commercial one.

Fig. 4. (a) Time-dependent UV-vis absorbance spectroscopic data obtained after mixing $\mathrm{Zn}^{2+}$ and 2-MeIM with a T-type micromixer; (b) time course of absorbance at $500 \mathrm{~nm}$ obtained by recording the absorbance continuously ( $0.1 \mathrm{~s}$ intervals). DI water was used to obtain the background spectrum.

Fig. 5. Median size of resulting ZIF-8 particles prepared with a batch reactor system. The same experiment was carried out 20 times under the same conditions.

Fig. 6. Relationship between flow rates of raw materials and size of resultant ZIF-8 particles. Reynolds number was calculated from flow rates.

Fig. 7. SEM images of ZIF-8 nanoparticles obtained at flow rates of (a) $1 \mathrm{ml} \cdot \mathrm{min}^{-1}$ and (b) 30 
$\mathrm{ml} \cdot \min ^{-1}$

Fig. 8. Median size of resulting ZIF-8 nanoparticles versus temperature.

Fig. 9. Relationship between raw material ratios $\left([2-\mathrm{MeIM}] /\left[\mathrm{Zn}^{2+}\right]\right)$ and the median size of ZIF-8 nanoparticles. The stoichiometric ratio of the coordination reaction between $2-\mathrm{MeIM}$ and $\mathrm{Zn}^{2+}$ ions is 2. The final concentration of $\mathrm{Zn}^{2+}$ ions was fixed at $0.025 \mathrm{M}$.

Fig. 10. Schematic control of a nucleation process and a particle growth process in synthesis of ZIF-8 nanoparticles.

Fig. 11. (a) $\mathrm{N}_{2}$ gas adsorption isotherms and (b) adsorption kinetics of an as-synthesized ZIF-8 sample with smaller particle size and a commercial one at $77 \mathrm{~K}$. The filled and open symbols described in (a) represent adsorption and desorption, respectively. 


\section{References}

[1] S. Kitagawa, R. Kitaura, S. Noro, Functional porous coordination polymers, Angew. Chem.-Int. Edit., 43 (2004) 2334-2375.

[2] G. Ferey, Hybrid porous solids: past, present, future, Chem. Soc. Rev., 37 (2008) 191-214.

[3] K.S. Park, Z. Ni, A.P. Cote, J.Y. Choi, R.D. Huang, F.J. Uribe-Romo, H.K. Chae, M. O'Keeffe, O.M. Yaghi, Exceptional chemical and thermal stability of zeolitic imidazolate frameworks, Proc.

Natl. Acad. Sci. U. S. A., 103 (2006) 10186-10191.

[4] H. Bux, F.Y. Liang, Y.S. Li, J. Cravillon, M. Wiebcke, J. Caro, Zeolitic Imidazolate Framework Membrane with Molecular Sieving Properties by Microwave-Assisted Solvothermal Synthesis, J. Am. Chem. Soc., 131 (2009) 16000-16001.

[5] S. Watanabe, H. Sugiyama, H. Adachi, H. Tanaka, M.T. Miyahara, Free energy analysis for adsorption-induced lattice transition of flexible coordination framework, J. Chem. Phys., 130 (2009) 5.

[6] P.Y. Moh, P. Cubillas, M.W. Anderson, M.P. Attfield, Revelation of the Molecular Assembly of the Nanoporous Metal Organic Framework ZIF-8, J. Am. Chem. Soc., 133 (2011) 13304-13307.

[7] T. Uemura, S. Kitagawa, Prussian blue nanoparticles protected by poly(vinylpyrrolidone), J. Am. Chem. Soc., 125 (2003) 7814-7815.

[8] S.H. Jhung, J.H. Lee, J.W. Yoon, C. Serre, G. Ferey, J.S. Chang, Microwave synthesis of 
chromium terephthalate MIL-101 and its benzene sorption ability, Adv. Mater., 19 (2007) 121-124.

[9] S. Hermes, T. Witte, T. Hikov, D. Zacher, S. Bahnmuller, G. Langstein, K. Huber, R.A. Fischer, Trapping metal-organic framework nanocrystals: An in-situ time-resolved light scattering study on the crystal growth of MOF-5 in solution, J. Am. Chem. Soc., 129 (2007) 5324-5325.

[10] J. Cravillon, S. Munzer, S.J. Lohmeier, A. Feldhoff, K. Huber, M. Wiebcke, Rapid Room-Temperature Synthesis and Characterization of Nanocrystals of a Prototypical Zeolitic Imidazolate Framework, Chem. Mat., 21 (2009) 1410-1412.

[11] D. Tanaka, A. Henke, K. Albrecht, M. Moeller, K. Nakagawa, S. Kitagawa, J. Groll, Rapid preparation of flexible porous coordination polymer nanocrystals with accelerated guest adsorption kinetics, Nat. Chem., 2 (2010) 410-416.

[12] S. Diring, S. Furukawa, Y. Takashima, T. Tsuruoka, S. Kitagawa, Controlled Multiscale Synthesis of Porous Coordination Polymer in Nano/Micro Regimes, Chem. Mat., 22 (2010) 4531-4538.

[13] M. Ma, D. Zacher, X.N. Zhang, R.A. Fischer, N. Metzler-Nolte, A Method for the Preparation of Highly Porous, Nanosized Crystals of Isoreticular Metal-Organic Frameworks, Cryst. Growth Des., 11 (2010) 185-189.

[14] Y.C. Pan, Y.Y. Liu, G.F. Zeng, L. Zhao, Z.P. Lai, Rapid synthesis of zeolitic imidazolate framework-8 (ZIF-8) nanocrystals in an aqueous system, Chem. Commun., 47 (2011) 2071-2073. 
[15] P. Guichardon, L. Falk, Characterisation of micromixing efficiency by the iodide-iodate reaction system. Part I: experimental procedure, Chem. Eng. Sci., 55 (2000) 4233-4243.

[16] P. Guichardon, L. Falk, J. Villermaux, Characterisation of micromixing efficiency by the iodide-iodate reaction system. Part II: kinetic study, Chem. Eng. Sci., 55 (2000) 4245-4253.

[17] A. Nagaki, M. Togai, S. Suga, N. Aoki, K. Mae, J. Yoshida, Control of extremely fast competitive consecutive reactions using micromixing. Selective Friedel-Crafts aminoalkylation, J. Am. Chem. Soc., 127 (2005) 11666-11675.

[18] P. Reuse, A. Renken, K. Haas-Santo, O. Gorke, K. Schubert, Hydrogen production for fuel cell application in an autothermal micro-channel reactor, Chem. Eng. J., 101 (2004) 133-141.

[19] J. Polte, R. Erler, A.F. Thunemann, S. Sokolov, T.T. Ahner, K. Rademann, F. Emmerling, R. Kraehnert, Nucleation and Growth of Gold Nanoparticles Studied via in situ Small Angle X-ray Scattering at Millisecond Time Resolution, ACS Nano, 4 (2010) 1076-1082.

[20] Y. Ying, G.W. Chen, Y.C. Zhao, S.L. Li, Q. Yuan, A high throughput methodology for continuous preparation of monodispersed nanocrystals in microfluidic reactors, Chem. Eng. J., 135 (2008) 209-215. 